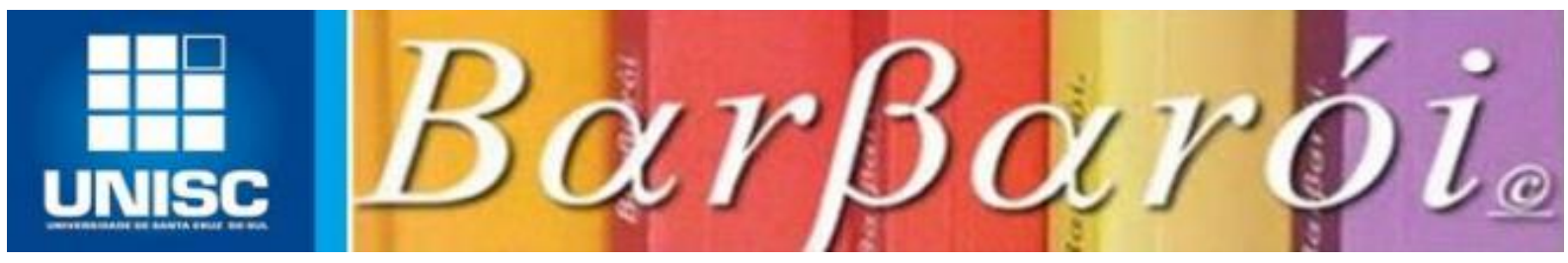

\title{
SÍNDROME DE BURNOUT: IMPLICAÇÕES CONFLITUOSAS ENTRE RELAÇÕES PROFISSIONẢIS E FAMILIARES
}

\section{DOI: http://dx.doi.org/10.17058/barbaroi.v51i1.4033}

Tiago Luan Labres Freitas

Universidade Federal da Fronteira do Sul - UFFS - Brasil

Jaqueline Ana Foschera

Universidade Federal da Fronteira do Sul - UFFS - Brasil

Vanessa Schneider

Universidade Federal da Fronteira do Sul - UFFS - Brasil

Maria Elisabete Calado Ramalho dos Santos

Universidade Federal da Fronteira do Sul - UFFS - Brasil

Lais Griebeler Hendges

Universidade Federal da Fronteira do Sul - UFFS - Brasil

Valéria de Bettio Mattos

Universidade Federal da Fronteira do Sul - UFFS - Brasil

\section{RESUMO}

A síndrome de Burnout caracteriza-se por um estado de esgotamento, decepção e perda do interesse pelo trabalho, produz sofrimento no indivíduo e tem consequências sobre o seu estado de saúde e o seu desempenho profissional. Acomete geralmente profissionais que trabalham em contato direto com pessoas, sendo predominante nos profissionais de saúde, como por exemplo, enfermeiros e profissionais da segurança pública, levando-os a desenvolver sentimentos de frustração, frieza e indiferença e sofrimento. O objetivo deste trabalho é identificar a prevalência do conflito entre trabalho e vida familiar em profissionais da área da saúde e segurança pública de determinada instituição governamental. Foi utilizado o método quantitativo para coleta de dados que contou com a participação de 25 pessoas, dentre estas médicos, técnicos de regulação médica, soldados e agentes. Conclui-se que ao confrontar as exigências do trabalho às do lar a necessidade de se estabelecer outra lógica de convivência qual foi imposta historicamente a homens e mulheres, que vai além de entendimento das demandas de trabalho e divisão de tarefas a fim de solucionar problemas para não transformar a relação família- trabalho em algo corrosivo e degradado.

Palavras-chave: Síndrome de Burnout, Família, Trabalho, Estresse.

\section{INTRODUÇÃO}

O estresse é uma resposta adaptativa e necessária ao ser humano, que o tem ajudado a sobreviver. Mas, quando é intenso, repetitivo e prolongado determina consequências 
preocupantes que podem lesar o bem-estar e a saúde do indivíduo. Reconhecidamente, os médicos, enfermeiros e professores ocupam o topo das profissões "estressantes" (PIRES, 2011).

O estresse contribui, de certo modo, para a sobrevivência e desenvolvimento dos seres humanos, para um rendimento eficaz nas suas atividades e para um desempenho relevante nas distintas áreas da vida. Contudo, caso o estresse seja excessivo e/ou difícil de controlar pode tornar se prejudicial ao individuo e acarreta prováveis consequências negativas para a saúde e o bem-estar psicológico, e nesta situação o individuo experiência situações desagradáveis em termos pessoais, familiares, sociais e profissionais. Neste sentido a própria conceitualização de estresse, pode articular-se com o conceito de bem-estar, com base na distinção entre situações de estresse positivo e estresse negativo. A literatura emprega este último termo de estresse para abranger a ansiedade e a depressão (BORGES, 2012).

A síndrome de Burnout traduz o esgotamento profissional com importantes repercussões no nível físico e psicológico derivados do estresse. Afeta o desempenho profissional, o relacionamento interpessoal, a produtividade, mas também a qualidade de vida do indivíduo e a dinâmica da organização no qual ele está inserido profissionalmente (PIRES, 2011).

Apesar da sua definição não ser consensual, pode-se afirmar que Burnout é uma síndrome de fadiga ou de esgotamento profissional (físico e psicológico), que surge em profissões que tem mais diretamente contato com o público e que implicam relações de cuidado. O Burnout caracteriza-se por uma tripla caraterística: exaustão emocional, atitude fria e despersonalizada e realização profissional reduzida (PIRES, 2011).

O conceito de Burnout foi utilizado pela primeira vez por Brandley (1969), mas ficou conhecido a partir de 1974, através de Freudenberger, psicanalista que trabalhava com toxicodependentes em Nova York. Ele constatou que alguns voluntários apresentavam uma perda progressiva de energia, sintomas de ansiedade e depressão, até chegar ao esgotamento. Tornavam-se menos sensíveis e compreensivos, desmotivados e até agressivos, em relação aos doentes, com um tratamento distanciado e com tendência a culpá-los pelos seus próprios problemas (PIRES, 2011).

Esta síndrome pode ser considerada uma explicação para as dificuldades encontradas no trabalho, cuja atividade profissional, seja como professor ou profissional da área da saúde e segurança, exige o contato direto com pessoas, que necessitam de atendimento integral. Estas dificuldades repercutem também na relação com a família. O trabalhador em crise começa a tratar e atendê-los de forma desumanizada, realizando suas atividades de maneira 
mecanizada, desvalorizando as pessoas na sua integralidade (SOUZA; SILVA, 2002)

Com efeito, o Burnout compreendido como conceito relacionado ao trabalho, foi introduzido por Freudenberger (1974), para identificar um estado de fadiga física e mental, que surge em inúmeros profissionais e que evoca a imagem da "bateria descarregada" ou da "vela que se apaga". De acordo com o autor, o Burnout deve ser compreendido como um conjunto de sintomas médico-biológicos e psicossociais, resultantes de uma exigência excessiva no trabalho. Na década de 1980, ocorreu uma sistematização das abordagens acerca da síndrome. Para tal contribuíram um conjunto de fatores, nomeadamente a compreensão do Burnout como síndrome tridimensional incluindo sintomas de exaustão emocional, despersonalização e perda de realização pessoal no trabalho. Outro contributo para a compreensão deste conceito refere-se à adoção de um conjunto restrito de questionários estandardizados. Considerando o constructo tridimensional, a síndrome de Burnout apresenta três dimensões que se interligam: a exaustão, o cinismo e a realização pessoal, que perante diferentes variáveis refletem diferentes comportamentos observáveis. (BORGES, 2012)

As pessoas que são acometidas por Burnout parecem ser as mais dedicadas, sendo um dos sintomas a queda da qualidade de serviços prestados. A síndrome vincula-se à falta de sono (insônia), o abuso no uso de álcool e drogas, problemas de relacionamento interpessoal, incluindo aqueles relacionados à família. Vários estudos comprovam que a relação trabalhofamília tem uma ligação e que há um conflito nos inter-papéis que ocorrem quando as exigências no trabalho e na família são extremamente incompatíveis. Este conflito também está relacionado ao aparecimento de Burnout (SOUZA; SILVA, 2002).

A OMS (Organização Mundial da Saúde) considera a síndrome de Burnout como um dos problemas de saúde mais graves da atualidade, não só pela alta prevalência do fenômeno entre profissionais de saúde, como também pelas possíveis consequências na população assistida por esses profissionais (PIRES, 2011). Isso se aplica de maneira muito clara e profunda a esses profissionais, pelas atividades profundamente relacionadas ao seu envolvimento emocional nas problemáticas dos pacientes. O profissional para criar o vínculo, acaba entrando no contexto da história de vida e patológica do enfermo, acrescido pelo fato da carga de trabalho ser exaustiva assomada à grande falta de valorização da categoria de trabalhadores da área da saúde (OLIVEIRA, 2009).

Nessa lógica, os profissionais acabam desenvolvendo sentimentos de frustração em sua vida tanto profissional quanto particular, podendo interferir na execução do seu trabalho. Ao não se sentirem realizados no que fazem, a consequência que mais se reflete é o desligamento parcial tanto no meio profissional como no familiar (vida particular), muitas 
vezes acarretando em conflito de sentimentos e anseios relacionados às diferentes esferas da vida social (OLIVEIRA, 2009).

Desilusão é a palavra que mais tem ligação com Burnout. O profissional que depositou esperanças e sonhos no bom desenvolvimento de seu trabalho e que poderia ocasionar a melhoria de vida para sua família, às vezes não consegue realizá-los pela alta cobrança de profissionais que ocupam postos superiores, bem como pela desvalorização profissional no seu ambiente de trabalho. Ocorre desilusão acerca das suas expectativas profissionais, o que o desanima para continuar a lutar por aquilo que gostaria de adquirir em termos de bens materiais. Por sua vez, a família como não o compreende pode culpá-lo por não terem o conforto que queriam, ocasionando situações desagradáveis para ambas às partes, com impacto no seu trabalho, acabando por desencadear estresse cumulativo, juntando estresse particular ao do trabalho (SOUZA; SILVA, 2002).

O conflito entre trabalho e família pode ser caracterizado por vários seguimentos estressores, como, por exemplo, que a grande massa populacional, passa maior parte do tempo produtivo do dia no trabalho. Muitas vezes, vêm à tona pensamentos de que o trabalho rouba um tempo que poderia ser dedicado à família, perdendo detalhes do crescimento dos filhos, dando pouca atenção aos pais, ou ainda, cuidando pouco dos relacionamentos afetivos ou ainda pensam que naquele tempo ele poderia se dedicar ainda mais para si mesmo, cuidar de si, procurar algo que o satisfaça e tenha resultado positivo em sua vida (AGUIAR, 2012).

O problema do conflito é enfocado sob o prisma de como ou quanto o trabalho "rouba" o tempo que o trabalhador poderia estar junto à família, ou seja, como na sua percepção, a família foi roubada do seu convívio em função de seu trabalho. Assim, a relação trabalho x família é uma relação biunívoca, onde o trabalho afeta a família e a família afeta o trabalho (MENEZES; CODO; MEDEIROS, 1999, p.99). Por mais que se preconize que os problemas de casa não são ou não devem ser levados para o trabalho e vice-versa, sabe-se que isso não é possível de acontecer por se tratar de seres humanos. Uma situação é reconhecer que a relação trabalho x família existe, que tanto no trabalho quanto na família existem afetos; outra é reconhecer que existem demandas numa e noutra situação que podem gerar conflitos. São com estas demandas e com as suas consequências que grande parte de estudiosos da área estão preocupados (SOUZA; SILVA, 2002).

Além disso, a família dos profissionais acaba sendo envolvida na situação, que consequentemente acaba resultando em conflitos internos no lar, o que por muitas vezes distancia a pessoa acometida pela síndrome e a sua respectiva família, sendo esta não reconhece o que se passa com seu ente. Sem o apoio familiar e conhecimento da situação 
pelos membros, há piora a relação entre os membros o que acaba geralmente distanciando seus laços familiares (SOUZA; SILVA, 2002).

Levando-se em conta que esses conflitos nem sempre são solucionados, a pessoa que está passando por essa situação acaba gerando não só problemas psicológicos, mas com o passar do tempo o estresse desenvolvido frequentemente ocasiona algumas patologias físicas e psicológicas, piorando ainda mais a situação da pessoa, dificultando assim a resolução dessa síndrome (PEREIRA; QUEIROZ, 2013).

O excesso de trabalho, falta de controle emocional, cobrança excessiva, falta de apoio e união no trabalho e a não existência de recompensa equivalente ao trabalho realizado, são alguns fatores que afetam o bem-estar físico e mental das pessoas, o que os torna mais suscetíveis ao aparecimento de Burnout. O que preocupa e gera consequências negativas não só à família, mas também à organização na qual a pessoa trabalha, pois sua produtividade pode diminuir (VOLPATO, 2002).

A atividade laboral hospitalar é caracterizada por excessiva carga de trabalho, contato com situações limitantes, alto nível de tensão e de riscos para si e para outros. Inclui problemas de relacionamento interpessoal aos que prestam assistência direta aos clientes e preocupações com demandas institucionais. A equipe de enfermagem, por sua própria natureza e características de seu trabalho, revela-se suscetível ao fenômeno do estresse ocupacional em decorrência da responsabilidade pela vida e a proximidade com os clientes para os quais o sofrimento é quase inevitável. Exige-se destes profissionais a dedicação no desempenho de suas funções, o que aumenta a possibilidade de ocorrência de desgastes emocionais em altos níveis de estresse, tornando-os vulneráveis à cronificação do estresse ocupacional que se denomina de Síndrome de Burnout (MENEGHINI; PAZ; LAUTERT 2011).

Enfermeiros, técnicos e auxiliares de enfermagem fazem parte de uma profissão caracterizada por ter, em sua essência, o cuidado e por grande parte da carga de trabalho ser o contato direto com pacientes e familiares. Do ponto de vista da organização do trabalho, a indefinição do papel profissional, a sobrecarga de trabalho frequentemente justificada por falta de pessoal e estimulada pelo pagamento de horas-extras, a falta de autonomia e autoridade na tomada de decisões, entre outras, geram um estado de estresse crônico, identificando-se como uma das profissões de maior incidência de Burnout (MOREIRA, et.al, 2009).

Segundo Teixeira (2012), os primeiros estudos que investigaram o Burnout em enfermeiros mostraram que a síndrome estava positivamente correlacionada à quantidade de 
tempo que os enfermeiros passam com os doentes, com a intensidade das exigências emocionais destes e com o cuidar de doentes com mau prognóstico. Os estudos mais recentes, diz a mesma autora, mostram que a síndrome está associada a fatores relacionados ao trabalho, tais como sobrecarga laboral, baixo nível de suporte, conflitos interpessoais, contato com a morte e preparação inadequada. A autora percebeu a ocorrência de Burnout em profissionais (enfermeiros, técnicos e auxiliares) num hospital brasileiro, cujos sintomas apresentavam-se da seguinte forma: enfermeiros tinham maiores níveis de exaustão emocional quando comparados com os técnicos e auxiliares, sendo a exaustão emocional maior nos enfermeiros com menor tempo de experiência profissional.

Farber (1991) refere que os profissionais afetados têm em comum o fato de serem trabalhadores encarregados "de cuidar", ou seja, possuem relações diretas com o usuário. Seu trabalho caracteriza-se pela assistência a pessoas que necessitam e deles exigem cuidado e atenção, pois estão doentes ou dependentes, sofrendo e gerando sentimentos na própria relação (ansiedade, angústia, dor, raiva, tristeza e desesperança), ou causando sentimentos no profissional como frustração, impotência ou apego. Subsidiando bibliograficamente nos pensamentos deste autor, foram apontados como populações de risco os professores, médicos, fisioterapeutas, dentistas, agentes penitenciários, policiais, entre outros (MAYER, 2002).

Acredita-se no contexto capitalista da realidade mundial, estes profissionais são os mais afetados pela síndrome, pois implementam uma postura humanística em lugares desumanizados como, por exemplo, o sistema de saúde, educação ou penitenciário (MAYER,2002).

A partir da literatura consultada, este trabalho pretende analisar por meio de pesquisa empírica, as relações, os conflitos geradores da Síndrome de Burnout e os reflexos destes na vida da classe de trabalhadores da saúde e segurança pública, em contato direto diariamente com pessoas, cuja jornada de trabalho é intensa e os sujeita aos contato direto com pessoas que usufruem do serviço.

\section{OBJETIVO}

Este trabalho possui o intuito de identificar a presença do conflito entre trabalho e vida familiar em trabalhadores da área da saúde e segurança pública do CRE - Centro e Regional Emergências da cidade de Chapecó-SC. A pesquisa que subsidia este artigo busca identificar os fatores causais do estresse, sentimentos de desuso ou frustração profissional e familiar, e como isso se reflete em ambos os contextos, de maneira a ocasionar o afastamento psicológico decorrente do grande conflito iminente. 


\section{METODOLOGIA}

Trate-se uma pesquisa quantitativa e qualitativa, realizada no mês de julho de 2013, a qual teve como campo de investigação a CRE - Central Regional de Emergências, anexo ao $2^{\circ}$ Batalhão de Polícia Militar de Chapecó.

A CRE conta com o serviço integrado da Polícia Militar de Santa Catarina e o SAMU - Serviço de Atendimento Móvel de Urgência. Foram convidados a participar da pesquisa de forma voluntária 25 trabalhadores de ambos os serviços, os quais receberam informações concernentes à síndrome e orientados quanto ao teor da pesquisa, posteriormente assinado o termo de Consentimento Livre e Esclarecido. O instrumento utilizado para coleta de dados foi um questionário com 12 questões de múltipla escolha.

Entende-se como profissionais constituintes da equipe participante da pesquisa, médicos, técnico auxiliar de regulação médica, rádio operador, soldados e agentes temporários da polícia militar. A pesquisa abre esse leque para todos os profissionais envolvidos (como por exemplo, soldados e técnico auxiliar de regulação), pois de alguma maneira são acometidos pelo estresse relacionado às problemáticas do trabalho da área da saúde e segurança pública.

\section{ESTRESSORES NO TRABALHO e QUALIDADE DE VIDA}

Segundo Mayer (2002), os estressores ocupacionais estão divididos em dois grupos distintos: 1) estressores do ambiente físico; e 2) demandas estressantes do trabalho e de seu conteúdo. Os primeiros referem-se a ruídos, vibração, qualidade de iluminação, temperatura, higiene, ventilação, adequação de espaço físico, dentre outros fatores. Todos esses estressores podem trazer consequências psicológicas e ergonômicas para a saúde do trabalhador. Dentre às demandas estressantes do trabalho e de seu conteúdo (execução da tarefa em si) os fatores que deste grupo fazem parte, cabe salientar:

- Sobrecarga de trabalho: ocorre tanto em termos qualitativos como quantitativos e é considerada a causa do estresse. O referido autor descreve que essas sobrecargas de trabalho produzem sintomas de estresse físico e psicológico e assim os enumera: tensão e insatisfação no trabalho, ansiedade, sensação de ameaça, redução da autoestima, elevação do nível de colesterol circulante, aumento da taxa cardíaca e predisposição ao consumo de tabaco. $\mathrm{O}$ excesso de horas trabalhadas reduz a possibilidade de apoio social do indivíduo;

- Relações interpessoais no trabalho: boas relações entre pessoas que compõem o grupo de trabalho são fatores fundamentais para a saúde pessoal e organizacional. A má qualidade das relações interpessoais é potencializadora de agentes estressores. O conflito pode gerar 
crescimento e estimular novas soluções, mas, se contínuo, gerará frustração, tensão, doenças psicossomáticas e outros males;

- Estágios de desenvolvimento da carreira profissional: relaciona-se a fase inicial de desenvolvimento da carreira com discrepâncias entre expectativas e realidade. A fase de consolidação da carreira é dedicada à busca de equilíbrio entre as demandas familiares e a própria carreira. A manutenção da carreira pode gerar estresse à medida que é constatado o êxito na carreira e o fracasso na vida pessoal. A última etapa refere-se ao estresse causado pela evidência do envelhecimento do indivíduo marcada pela aposentadoria;

- Status profissional e salário: Se não há perspectiva de melhoria da condição, maior a possibilidade de estresse. O autor mostra que a satisfação obtida em relação ao trabalho é dependente da percepção de sua equidade por parte do trabalhador. Para Peiró (1992), elevado status corresponde a salário mais alto e consequentemente maior satisfação;

- Novidade ou variedade das tarefas: o trabalho rotineiro e contínuo, durante longos anos, torna o trabalhador menos flexível e mais predisposto ao estresse. Em contrapartida, quando ocorre excesso de mudanças de tarefa o estresse também pode se estabelecer;

- Ambiguidade de funções: a ambiguidade ocorre quando membros do grupo de trabalho têm expectativas ou demandas incompatíveis entre si. Denomina-se também ambiguidade de funções a sobrecarga decorrente de acúmulo de obrigações e responsabilidades provenientes de uma ou várias funções que a pessoa desempenha;

- Controle de atividades: Essa variável diz respeito à possibilidade que o indivíduo tem de controle das atividades que realiza no nível intrínseco (planificação e procedimentos) e extrínseco (salários, benefícios e horários) do ambiente de trabalho. Quanto mais controle o indivíduo possui, menor a possibilidade da elevação da tensão ou surgimento do estresse.

\section{ANÁLISE DOS DADOS}

Entre os pesquisados, $60 \%$ eram do sexo masculino e $40 \%$ do sexo feminino (FIGURA 1), com idade entre 21 e 57 anos, dentre estes, $48 \%$ declararam-se casados, $48 \%$ solteiros e 4\% divorciados (FIGURA 2). Do total de entrevistados, $4 \%$ residem sozinhos e possuem animais de estimação. Os demais participantes, ou seja, 96\% residem com algum membro da família (FIGURA 2). 

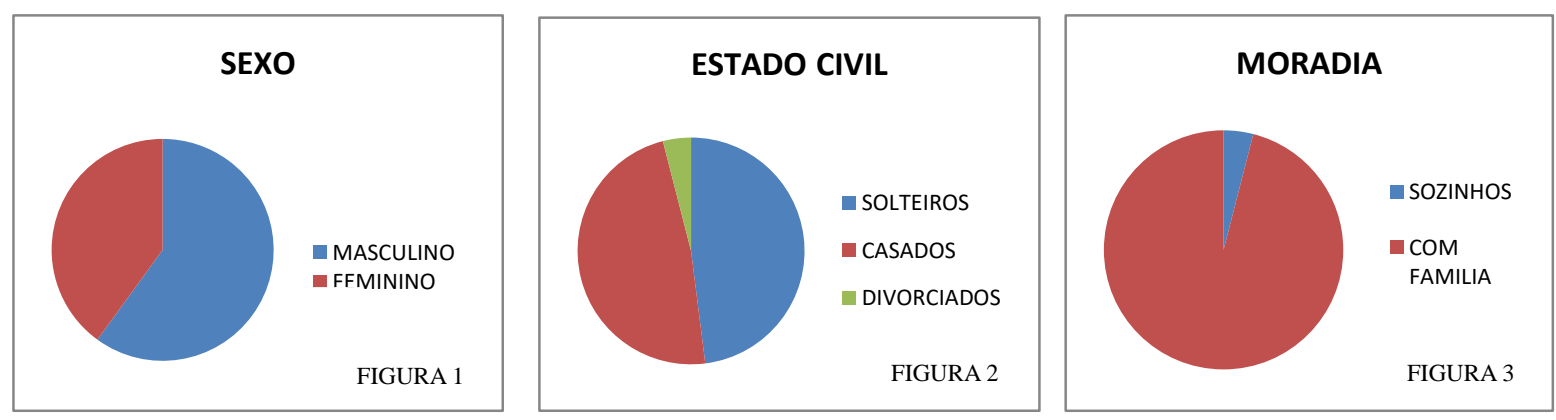

Quando questionados sobre como ocupam o seu tempo, $84 \%$ dos entrevistados declararam ter pouco ou nenhum tempo para convivência familiar e $100 \%$ dos entrevistados afirmam dispender tempo relevante com o trabalho. Quanto ao tempo disponível para si, $40 \%$ dos entrevistados declara ter pouco tempo e $60 \%$ que dispõem de tempo suficiente. Entre os pesquisados, 64\% afirma ter pouco tempo para os estudos e 68\% para o lazer. Dos entrevistados que declara ser casados, 66\% afirmam ter pouco tempo para o cônjuge e dos entrevistados que declararam ter filhos (40\% do total) $50 \%$ destes afirmaram ter pouco tempo para os mesmos.

Quando questionados sobre como se sentem no ambiente trabalho, 24\% afirmaram sentir-se emocionalmente exaustos, $16 \%$ afirma sentir-se desmotivados quando levantam pela manhã e têm que trabalhar. Também $16 \%$ disseram que o fato de trabalhar diretamente com pessoas todos os dias lhes gera estresse.

Ainda relacionado ao ambiente de trabalho, 28\% afirmaram que o trabalho lhes causa algum tipo de esgotamento físico, e $28 \%$ disseram ter perda do entusiasmo com o trabalho, $28 \%$ não se sentem bem naquilo que fazem, porém a grande maioria, $92 \%$ resolvem com eficácia os problemas que aparecem em seu ambiente de trabalho. Dos entrevistados, 12\% não se sentem alegre ao atingir as metas de trabalho e $40 \%$ afirmaram não ter conseguido realizações com seu trabalho.

Quanto aos questionamentos sobre as características que representam seu ambiente familiar, $20 \%$ atestaram que o estresse está normalmente presente, assim como $28 \%$ para presença de ansiedade e $8 \%$ a presença de sofrimento. Contrastando com estes dados, os pesquisados também afirmam a presença de felicidade (76\%), bem-estar (76\%) e satisfação (64\%) com normalidade, respectivamente.

Os entrevistados foram questionados sobre como classificam o seu bem-estar familiar comparado a outras famílias, $8 \%$ declararam sentir seu bem-estar muito inferior ao de outras famílias, e $12 \%$ declararam razoavelmente inferior.

Ao serem indagados nos questionamentos sobre quanto o trabalho influencia nos 
diferentes aspectos de suas vidas, 20\% declarou que o trabalho influencia suas relações sociais com frequência, $24 \%$ afirma que o trabalho influencia com normalidade em seu nível de estresse, $32 \%$ diz que o trabalho influencia suas relações familiares com frequência, $40 \%$ falam que o trabalho influencia em seu bem estar individual e lazer com normalidade.

Ainda relacionado a esses aspectos, constata-se que em $20 \%$ dos casos o trabalho influencia na satisfação das necessidades emocionais com frequência, e ocorre também $24 \%$ de influência cotidiana na satisfação das necessidades sexuais. Nos casados, $52 \%$ declarou que o trabalho influencia com normalidade suas relações conjugais.

A grande maioria relata ser muito importante em sua vida familiar a presença de bemestar (92\%), felicidade (84\%), experiências como viagens, lazer e cultura (64\%), relações sociais (60\%), satisfação sexual (60\%) e diálogo (80\%), já o quesito normalidade foi julgado "muito importante" por apenas $28 \%$ dos entrevistados.

Quando perguntados sobre como reagem em momentos críticos, o que mais chama atenção é que $36 \%$ declaram que frequentemente ficam zangados, $4 \%$ nunca mantém o controle, $32 \%$ normalmente ficam frustrados, $20 \%$ nunca se sentem otimistas, $16 \%$ normalmente se sentem deprimidos, $40 \%$ nunca procuram ajuda externa, $28 \%$ sentem-se normalmente cansados, $8 \%$ agem com agressividade, $24 \%$ ficam normalmente ansiosos e $4 \%$ nunca ficam reflexivos.

Quando questionados sobre os motivos que ocasionam estes momentos críticos $24 \%$ afirmaram que estes ocorrem em função do excesso de trabalho, 36\% devido ao estresse emocional frequente, $24 \%$ devido a problemas familiares, $16 \%$ devido à insatisfação no trabalho, e 16\% devido a decepções familiares.

\section{DISCUSSÕES DOS DADOS}

A discussão dos dados baseia-se nos estudos de Menezes, Codo e Medeiros (1999), que em seu trabalho sustenta que toda relação de trabalho faz parte de um sistema maior ao qual pode-se chamar de social, uma vez que o ser humano vende sua força de trabalho para em troca a satisfação de necessidades materiais (casa, alimentação, roupa, lazer, etc.) ou afetivas (reconhecimento, satisfação, etc.).

O trabalho parece que 'rouba' mesmo um tempo ou afeto que pertence à família e vice-versa. É comum se ouvir de muitos profissionais, como, professores, por exemplo, a existência de um ciclo repetitivo de sobrecarga de trabalho cujo resultado não poderia ser outro: sofrimento psíquico, exaustão emocional e despersonalização (MENEZES; CODO; MEDEIROS, 1999, p.99): 
“... sou do tipo que leva trabalho para casa... às vezes acho que roubo o tempo da família. É assim mesmo, estas atividades precisam ser feitas, aonde e quando vou corrigir as provas e os trabalhos? Sinto que deveria dividir mais as atenções entre a casa e a escola, mas tem momentos que isso é impossível...”.

Pode ser observado com estes dados, que o excesso de tempo no trabalho está relacionado ao rompimento de vínculos familiares, nota-se que o fato de interromper os estudos para se dedicar ao trabalho, pode causar desapontamento, pois a falta de continuidade dos estudos gera estagnação social que, associada ao pouco tempo dedicado para si pode causar adoecimento psíquico.

Além disso, o fato de possuir um cônjuge ou companheiro de nada garante a disponibilidade afetiva mesmo quando este é representado como um importante suporte, pois nem sempre o mesmo se mostra disponível ou suficiente para gerar o apoio psíquico necessário (MENEZES; CODO; MEDEIROS, 1999, p.99):

No caso dos filhos, é fato que os mesmos complementam a vida afetivamente, mas em geral não é a eles que os pais recorrem quando precisam de ajuda, ainda mais se forem pequenos, são eles que precisam de atenção não podendo contribuir para ajuda emocional e psíquica dos pais. Quando adolescentes preferem a liberdade e se forem adultos constroem sua própria família, muitas vezes longe dos pais (MENEZES; CODO; MEDEIROS, 1999, p.99):

Ao se confrontar as exigências atuais do trabalho e do lar com o papel que foi historicamente conferido aos homens e às mulheres, há necessidade de se estabelecer outra lógica de convivência que passa por muito mais entendimento, divisão de tarefas, cooperação, companheirismo. É nessa esfera que o problema deve ser encarado. É nessa esfera que deve ser entendido e solucionado antes de vir a se transformar em outro, corrosivo, tanto da relação pessoal, quanto da relação de trabalho, do tipo como tal aparece no relato anterior (MENEZES; CODO; MEDEIROS, 1999, p.99):

A organização e as condições de trabalho, além das constantes vivências de dor parecem chocar-se frontalmente com a esfera das aspirações, das motivações e dos desejos. O sujeito, então, passa a reavaliar os aspectos negativos dos seus afazer, podendo atribuir-lhe, ou não, um caráter penoso e de menos valia, o que dentre outras coisas pode gerar respostas desde a frustração, até o boicote ou desistência. Diante deste quadro no qual se apresenta o trabalhador, é preciso haver um equacionamento de expectativas e frustrações, de forma a propiciar ao profissional o mínimo de recompensa e satisfação necessária para se sentir motivado e em 
condições físicas, sociais e emocionais, para a execução significativa de determinada tarefa (ALVES, 2005)

\title{
7. CONCLUSÕES
}

A orientação de um trabalho de forma mais humanizada diminui significativamente os índices de possibilidade de ocorrência de Burnout. As empresas precisam voltar, cada vez mais, a sua atenção para as questões que envolvem a saúde mental dos profissionais. As repercussões pessoais e organizacionais do adoecimento no trabalho geram efeitos nocivos para toda a relação social do indivíduo. Todas as dimensões da doença associam-se à auto percepção de que as forças físicas, psíquicas e mentais estão se esgotando. Para tanto, o conhecimento das características e fatores desencadeantes da síndrome, suas características, sintomas e diagnósticos são fundamentais para que se possa por em prática estratégias de prevenção e intervenção nas organizações (FERRARI; FRAÇA; MAGALHÃES, 2012).

Com a realização deste estudo, pode-se observar claramente, que o excesso de tempo no trabalho e dedicação ao mesmo, está relacionado ao rompimento de vínculos familiares, bem como o aparecimento de conflitos advindos desta realidade. Com os dados obtidos na pesquisa, alicerçando-se no estudo de Aguiar, 2012, afirma-se que a incidências de Burnout é algo presente em grande parte das classes trabalhadoras que seus serviços exijam contato direto com a população.

\section{BURNOUT SYNDROME: IMPLICATIONS CONFLICTING RELATIONS BETWEEN PROFESSIONALS AND FAMILY}

\begin{abstract}
Burnout syndrome is characterized by a state of exhaustion, disappointment and loss of interest in work, produces suffering in individual and has consequences on their health status and their professional performance. It is mostly professionals who work in direct contact with people, being prevalent in health professionals, such as nurses and public security, leading them to develop feelings of frustration, coldness and indifference and suffering. The objective of this work is to identify the prevalence of conflict between work and family life in professional health and public safety of a particular government institution. Method was used to collect quantitative data that was attended by 25 people from these doctors, technicians, medical regulation, soldiers and police. We conclude that in confronting the demands of work at home the need to establish another logic of coexistence which has been imposed historically men and women, that goes beyond understanding the demands of work and division of labor in order to solve problems not transform the work-family relationship into something corrosive and degraded.
\end{abstract}


Keywords: Burnout Syndrome, Family, Work, Stress.

\section{SÍNDROME DE BURNOUT: IMPLICACIONES RELACIONES CONFLICTIVAS ENTRE PROFESIONALES Y FAMILIA}

\section{Resumen}

El síndrome de Burnout se caracteriza por un estado de agotamiento, decepción y pérdida de interés en el trabajo, produce sufrimiento individual y tiene consecuencias sobre su estado de salud y su desempeño profesional. Es en su mayoría profesionales que trabajan en contacto directo con la gente, siendo frecuente en profesionales de la salud, como enfermeras y la seguridad pública, lo que lleva a desarrollar sentimientos de frustración, la frialdad y la indiferencia y el sufrimiento. El objetivo de este trabajo es identificar la prevalencia de los conflictos entre el trabajo y la vida familiar en el profesional de la salud y la seguridad pública de una institución gubernamental en particular. El método se utiliza para recoger datos cuantitativos que asistieron 25 personas de estos médicos, técnicos, regulación médica, soldados y policías. Llegamos a la conclusión de que para enfrentar las exigencias del trabajo en el país la necesidad de establecer otra lógica de la convivencia que se ha impuesto históricamente, los hombres y mujeres, que va más allá de la comprensión de las exigencias del trabajo y la división del trabajo con el fin de resolver los problemas no transformar la relación trabajo-familia en algo corrosivo y degradado.

Palabras clave: Síndrome de Burnout, la familia, el trabajo, el estrés.

\section{REFERÊNCIAS}

AGUIAR, C. V, Conflito trabalho-família e comprometimento organizacional: Um estudo com trabalhadores de diferentes segmentos produtivos. Salvador, 106 f. Dissertação (Pósgraduação) - Curso de Psicologia, Universidade Federal da Bahia, 2012.

ALVES, C. F. O. Entre o cuidar e o sofrer: o cuidado do cuidador via experiência de cuidadores/profissionais de saúde mental. Recife, 177 f. Dissertação (Mestrado) Universidade Católica de Pernambuco, 2005

BORGES, S. O contributo do distress, burnout e do bem-estar para o absentismo e satisfação: Um estudo com trabalhadores da administração pública em contexto universitário. Almada, 83 f. Dissertação (Mestrado) - Instituto Piaget, 2012.

FARBER, B. A. Crisis in education: stress and Burnout in the American teacher. São Francisco: Jossey- Bass, 1991

FERRARI, R., FRANÇA, F. M., MAGALHÃES, J. Avaliação da síndrome de burnout em profissionais de saúde: uma revisão integrativa da literatura. Revista Eletrônica Gestão \& Saúde, Brasília, Vol.03, №. 03, p 1150-1165, 2012

MAYER, V. M. Síndrome de Burnout e qualidade de vida profissional em policiais militares

Barbarói, Santa Cruz do Sul, n.51, p.<212-226>, jan/jun, 2018 
de Campo Grande-MS. Campo Grande, 177 f. Dissertação (Mestrado) - Universidade Católica Dom Bosco, 2002.

MENEGHINI, F., PAZ, A. A., LAUTERT, L. Fatores ocupacionais associados aos componentes da síndrome de Burnout em trabalhadores de enfermagem. Contexto Enfermagem, Florianópolis, Vol. 20 No 2, p 225-233, 2011

MENEZES, I. V., CODO, W., MEDEIROS, L. Educação: carinho e trabalho: o conflito entre o trabalho e a família e o sofrimento psíquico, cap. 14. Petrópolis: Ed. Vozes, 1999 p.99

MOREIRA, D. S., MAGNAGO, R. F., SAKAE, T.M., MAGAJEWSKI, F. R. L. Prevalência da Síndrome de Burnout em trabalhadores de enfermagem de um hospital de grande porte da região sul do Brasil. Cadernos de Saúde Pública, Rio de Janeiro, Vol. 25 No 7, p 1559-1568, 2009

OLIVEIRA, S.F.L. Conflito trabalho - família e o uso de práticas de suporte instrumental em empresas fabricantes de eletroeletrônicos de Caxias do Sul. Caxias do Sul, 116 f. Dissertação (Mestrado) - Curso de Administração, Universidade de Caxias do Sul, 2009

PEIRÓ, J. M. Psicología de la organización. Madrid: Universidad Nacional de Educación a Distancia, 1992

PEREIRA, A.M, C. Q. Preditores do Burnout: interação trabalho-família e satisfação profissional em enfermeiros, 2013. Disponível em: http://repositorioaberto.up.pt/handle/10216/67302mode=full\&submit_simple. Acesso em 20/08/2013.

PIRES, C.S.P. Stress e Burnout nos médicos de família de Coimbra no contexto dos dois modelos organizacionais dos cuidados de saúde primários, 2011. Disponível em: <https://estudogeral.sib.uc.pt/handle/10316/20417>. Acesso em: 01/08/2013.

SOUZA, W. C., SILVA, A. M. M. A influência de fatores de personalidade e de organização do trabalho no Burnout em profissionais de saúde. Rev. Estudos de Psicologia, Campinas, v. 19 , n. 1 p. $37-48,2002$

TEIXEIRA, M. O Burnout e os enfermeiros. 2012. Disponível em: http://br.monografias.com/trabalhos3/Burnout-enfermeiros/Burnout-enfermeiros.shtml. Acesso em: 02/08/2013

VOLPATO, D.C., GOMES, F.B., CASTRO, M. A. , BORGES, S.K. , JUSTO, T. , PEREIRA, A. M. T. B. Burnout em profissionais de Maringá. Revista Eletrônica InterAção Psy, Maringá Vol, $1 \mathrm{~N}^{\mathrm{o}}$ 1, p.102-111, 2002 


\section{Sobre os autores}

Tiago Luan Labres Freitas é Acadêmico do $6^{\circ}$ período do curso de bacharelado em Enfermagem da Universidade Federal da Fronteira Sul, campus Chapecó SC. Endereço eletrônico: tiagolabres@ hotmail.com

Jaqueline Ana Foschera é Acadêmica do $6^{\circ}$ período do curso de bacharelado em Enfermagem da Universidade Federal da Fronteira Sul, campus Chapecó SC. Endereço eletrônico: jaquefoschera@gmail.com

Vanessa Schneider é Acadêmica do $6^{\circ}$ período do curso de bacharelado em Enfermagem da Universidade Federal da Fronteira Sul, campus Chapecó SC. Endereço eletrônico: schneider.nessa@hotmail.com

Maria Elisabete Calado Ramalho dos Santos é Acadêmica do $6^{\circ}$ período do curso de bacharelado em Enfermagem da Universidade Federal da Fronteira Sul, campus Chapecó SC. Endereço eletrônico: mariaelisa_ramalho@hotmail.com

Lais Griebeler Hendges é Acadêmica do $6^{\circ}$ período do curso de bacharelado em Enfermagem da Universidade Federal da Fronteira Sul, campus Chapecó SC. Endereço eletrônico: lais.gh@hotmail.com

Valéria de Bettio Mattos é Psicóloga graduada pela UFSC, doutora em educação pela UFSC, professora Adjunta da Universidade Federal da Fronteira Sul, Campus Chapecó SC. Endereço eletrônico: valeriadebettio@gmail.com 